\title{
Altered Synapse Formation in the Adult Somatosensory Cortex of Brain-Derived Neurotrophic Factor Heterozygote Mice
}

\author{
Christel Genoud, ${ }^{1}$ Graham W. Knott, ${ }^{1}$ Kazuko Sakata, ${ }^{2}$ Bai Lu, ${ }^{2}$ and Egbert Welker ${ }^{1}$ \\ ${ }^{1}$ Institut de Biologie Cellulaire et de Morphologie, 1005 Lausanne, Switzerland, and ${ }^{2}$ Section on Neural Development and Plasticity, National Institute of \\ Child Health and Human Development, Bethesda, Maryland 20892-4480
}

\begin{abstract}
Increased sensory stimulation in the adult whisker-to-barrel pathway induces the expression of BDNF as well as synapse formation in cortical layer IV. Here, we investigated whether BDNF plays a role in the alterations of connectivity between neurons by analyzing the ultrastructure of the BDNF heterozygote mouse, characterized by a reduced level of BDNF expression. Using serial section electron microscopy, we measured synapse density, spine morphology, and synaptic vesicle distribution to show that mice with a reduced level of BDNF have a barrel neuropil that is indistinguishable from wild-type controls. After $24 \mathrm{hr}$ of whisker stimulation, however, there is no indication of synapse formation in the heterozygous mouse. Whereas the balance between excitatory and inhibitory synapses is modified in the controls, it remains constant in the heterozygotes. The distribution of synaptic vesicles in excitatory synapses is the same in heterozygous and wild-type mice and is not influenced by the stimulation paradigm. Spine volume, however, is unchanged by stimulation in the wild-type animals, but does increase significantly in the heterozygous animal. These results provide evidence that, in vivo, BDNF plays an important role in the structural rearrangement of adult cortical circuitry as a consequence of an increased sensory input.
\end{abstract}

Key words: BDNF; barrel; plasticity; synapse; GABA; spine; ultrastructure

\section{Introduction}

During adulthood, altered sensory experience results in significant physiological changes in the somatosensory cortex (Welker et al., 1992; Fox et al., 1996; Bronchti et al., 1999; Gierdalski et al., 1999; Jones et al., 2002). These functional modifications are in parallel with structural changes, particularly at the level of the dendritic spine (Knott et al., 2002; Trachtenberg et al., 2002). Using two-photon microscopy, Trachtenberg et al. (2002) imaged dendritic spines in the mouse barrel cortex for a number of days in live adults. They showed that dendritic spines grow and retract during this period, and some form synapses as a function of altered sensory input. We have previously demonstrated that $24 \mathrm{hr}$ of continuous, passive stimulation of a single whisker induced an increase in the density of dendritic spines as well as an increase in spines with a second inhibitory synapse (Knott et al., 2002). Although the molecular basis of dendritic spine changes remain unknown, the increased expression of BDNF mRNA in response to the same stimulation paradigm (Rocamora et al., 1996) strongly implicates this neurotrophin in the process. Originally discovered for its effects on the growth and survival of

Received Sept. 2, 2003; revised Jan. 12, 2004; accepted Jan. 12, 2004.

This work was supported by a grant from the Swiss National Science Foundation (3100-062112.00). We thank Rudolf Kraftsik for help with the statistical analyses, Veronique Mamin and Caroline Musetti for technical assistance, Charles Quairiaux for help in measuring the BDNF levels in the barrel cortex, and the Centre of Electron Microscopy at the University of Lausanne for the use of its facilities.

Correspondence should be addressed to Dr. E. Welker, Institut de Biologie Cellulaire et de Morphologie, Rue du Bugnon 9, 1005 Lausanne, Switzerland. E-mail: Egbert.Welker@IBCM.unil.ch.

DOI:10.1523/JNEUROSCI.4040-03.2004

Copyright $\odot 2004$ Society for Neuroscience $\quad 0270-6474 / 04 / 242394-07 \$ 15.00 / 0$ developing neurons, BDNF is involved in synaptic plasticity, such as long-term potentiation (LTP) in the hippocampus (Korte et al., 1995; Figurov et al., 1996; Patterson et al., 1996), and in ocular dominance plasticity in the visual cortex (Cabelli et al., 1995; Huang et al., 1999).

In the present study, we investigated the role of BDNF in adult synaptogenesis by asking whether the reduced level of BDNF expression affects whisker stimulation-induced modification of synapses in the barrel cortex. BDNF heterozygote mice (BDNF $+/-$ ) have proved themselves to be a useful animal to study the role of BDNF in synaptic plasticity (Korte et al., 1995; PozzoMiller et al., 1999). For example, they exhibit an impairment in LTP, synaptic responses to tetanus, and the number of docked vesicles at the hippocampal CA1 synapses (Korte et al., 1995; Patterson et al., 1996; Pozzo-Miller et al., 1999). Using serial section electron microscopy and morphometric analyses, we determined synaptic density and analyzed the morphology of individual spines [for discussion and comparison of this method see Coggeshall and Lekan (1996) and Fiala and Harris (2001)]. Comparison of these parameters showed that the neuropil of BDNF $+/-$ mice is the same to wild-type mice. However, reduced expression of BDNF prevents an increase in synaptic density after $24 \mathrm{hr}$ of whisker stimulation. Whereas such stimulation induced a marked increase in the number of inhibitory synapses and in the number of spines with two synapses (one excitatory and one inhibitory) in the barrel cortex of the wild-type mice, neither occurred in the BDNF $+/-$ mice. Therefore, a certain level of $\mathrm{BDNF}$ is required to induce the formation of synapses and spines 
in the adult somatosensory cortex. To our knowledge, this is the first demonstration that activity-dependent control of synapse number in the adult cerebral cortex is mediated by BDNF.

\section{Materials and Methods}

Preparation of tissue lysates and ELISA quantification of BDNF. To measure BDNF protein levels in the barrel cortex, three pairs of 8- to 11week-old siblings (BDNF heterozygous and wild type) were killed by deep anesthesia. The barrel cortices from each mouse were removed, and the remaining brain was fixed via cardiac perfusion. Once fixed, $40 \mu \mathrm{m}$ frozen sections were cut tangential to the surface of somatosensory cortex and Nissl stained to confirm the exact region of barrel cortex that had been sampled. These two pieces of barrel cortex were pooled and homogenized by sonification in homogenization buffer (20 mM Tris, $\mathrm{pH} 7.5,150$ mм NaCl, $1 \%$ NP-40, 1 mm EDTA, $10 \mu \mathrm{g} / \mathrm{ml}$ aprotinin, $1 \mu \mathrm{g} / \mathrm{ml}$ leupeptine, $1 \mu \mathrm{g} / \mathrm{ml}$ pepstatine, and $1 \mathrm{~mm}$ PMSF), followed by centrifugation for $5 \mathrm{~min}$ at $12,000 \times \mathrm{g}$ at $4^{\circ} \mathrm{C}$. The quantity of total protein in the supernatants was assessed by protein assay (Bio-Rad Laboratories, Hercules, $\mathrm{CA})$, according to the manufacturer's instruction. BDNF protein levels were determined by ELISA (BDNF immunoassay system; Promega, Madison, WI) as described by the manufacturer. The value of the sample was normalized to the total soluble protein concentration, and the data were expressed as the mean $\pm \mathrm{SD}$.

Passive whisker stimulation protocol. BDNF heterozygote colony was raised from two pairs of BDNF heterozygous mice in C57/BL6 background (Ernfors et al., 1994). Three wild-type $(+/+)$ and four BDNF $+/-$ male littermates were stimulated according to the protocol described previously (Melzer et al., 1985; Welker et al., 1992; Knott et al., 2002), whereby a single piece of ferrous metal was glued to the left C2 whisker (1.5 mm long and $0.2 \mathrm{~mm}$ diameter) and the unanesthetised animals ( 2 months of age) were placed for $24 \mathrm{hr}$ in a cylindrical cage inside an electromagnetic coil delivering a burst of electromagnetic field at $8 \mathrm{~Hz}$. All procedures were reviewed and approved by the Office Veterinaire Cantonal (Lausanne), in accordance with Swiss Federal Laws.

Electron microscopy. Immediately after the $24 \mathrm{hr}$ stimulation period, mice were anesthetized with pentobarbital $(6 \mathrm{mg} / 100$ gm body weight, i.p.) and perfused intracardially with $300 \mathrm{ml}$ of fixative (2.5\% glutaraldehyde and $2 \%$ paraformaldehyde in cacodylate buffer $(0.1 \mathrm{M}), \mathrm{pH} 7.4$, with $3 \mathrm{~mm} \mathrm{CaCl})$. Brains were removed $60 \mathrm{~min}$ later and placed in the same fixative for an additional $60 \mathrm{~min}$. Vibratome sections $(80 \mu \mathrm{m}$ thick) orientated tangentially to the barrel cortex, were cut from the cortex, contralateral to the stimulated whisker, and rinsed in cacodylate buffer. Sections were then postfixed in osmium tetroxide ( $1 \%$ in cacodylate buffer) for $40 \mathrm{~min}$ and in uranyl acetate (1\% in water) for $30 \mathrm{~min}$. Sections were then dehydrated in alcohol and embedded in Durcapan ACM resin (Fluka, Neu-Ulm, Germany) between silicon-coated glass slides. Barrels B2 and C2 were identified, and ultrathin sections $(65 \mathrm{~nm}$ in thickness), on which both barrels were visible, were cut in series and collected on formvar-coated, single-slot gold grids.

Postembedding immunhistochemistry for GABA. The protocol was described previously by Knott et al. (2002). Briefly, the resin sections were etched in $1 \%$ periodic acid, followed by $1 \%$ sodium metaperiodate, and then pretreated in $20 \mathrm{~mm}$ TBS, pH 7.4, containing $0.5 \%$ BSA and $1 \%$ NGS. These were then incubated overnight at $4^{\circ} \mathrm{C}$ in anti-GABA antibody (catalog \#A2052; Sigma, St. Louis, MO) diluted at 1:1000 in the same buffer, followed by incubation for $120 \mathrm{~min}$ in goat anti-rabbit antibody coated with $15 \mathrm{~nm}$ gold particles (Aurion, Wageningen, Netherlands) diluted at 1:20. Sections were then rinsed in distilled water and contrasted twice with $1 \%$ uranyl acetate and lead citrate.

Acquisition of stacks of serial sections. Images of the sections were recorded using a Philips CM10 electron microscope. Once a region of neuropil, free of cell bodies and blood vessels, was found, images were captured using a digital camera (Digicam; Gatan, Munich, Germany) and the software Digimicrograph 2.5 (Gatan) at a final magnification of $10.5 \mathrm{~K}$. For each mouse, and, therefore, each series of sections, images were acquired in both the $\mathrm{B} 2$ and $\mathrm{C} 2$ barrels, which were on the same thin sections. Serial images were then aligned using Adobe Photoshop 6.0 (Adobe, Mountain View, CA).
Calculation of synaptic densities. To calculate the density of synapses from a series of images, the Neurolucida software was used (version 4.34; MicroBrightField, Williston, VT) to visualize the stack of images and place a counting square over the region of neuropil. The volume of each stack was calculated by multiplying the area of the counting square by the total thickness of sections. All sections were cut at $65 \mathrm{~nm}$ (a silver gray interference color), as indicated by the ultramicrotome (Ultracut UCT; Leica, Nussloch, Germany); this thickness was also verified by using the diameters of at least 20 mitochondria in each stack, as described previously in Knott et al. (2002). To count synapses, those touching the left and top sides of the counting frame were included in the count, whereas those touching the right and bottom sides were excluded. This procedure was performed by someone who did not know from which barrel or mice the images had been taken. Synapses are recognized as two-electrondense membranes separated by a synaptic cleft, the presynaptic element containing at least three synaptic vesicles. Each time a synapse was identified, it was counted only when it had disappeared in the subsequent images of the stack. They were classified by the nature of the presynaptic and postsynaptic elements. The presynaptic element was either classed as GABA positive or GABA negative. The postsynaptic element was identified as being either a spine or dendritic shaft and also whether or not it was GABA positive. Structures were considered as being GABA positive if more than three gold particles were seen to label the structure on each image in the stack that was visible. Dendritic spines were identified by their shape and size and the absence of microtubules and mitochondria. The majority of spines ( $>90 \%$ ) contained a spine apparatus.

Three-dimensional reconstructions. Entire spines were reconstructed from the image stacks including their synaptic density and the surface of contact with astrocytes. Astrocytic processes were identified by their irregular shape, the lack of microtubules, and a clear cytoplasm. The software Neuroexplorer (version 3.30; Microbrightfield) was then used to calculate the volume and surface area of spines, as well as the synaptic surface and surface area of contact with the astrocytes based on the contours drawn. The solid views of spines were obtained using the module Depthanalyzer of Imaris 2.7 (Bitplane, Zurich, Switzerland) on an Octane 2 (Silicon Graphics, Mountain View, CA) workstation.

Quantitative analysis of synaptic vesicles. To analyze the vesicles within synaptic boutons synapsing on dendritic spines, we used ultrathin sections that had not been used for GABA immunohistochemistry. Synapses were selected for counting based on the criteria defined previously by Pozzo-Miller et al. (1999). Briefly, only synapses with a length approximately equal to the width of the presynaptic bouton were used, to avoid bias introduced by larger synapses. Only asymmetric synapses on spines were photographed. Synaptic vesicles were only counted when their membranes could be seen for at least one-half of their circumference. A total of 264 synapses in wild-type mice $(n=3)$ and 242 synapses in BDNF $+/-$ mice $(n=3)$ were analyzed. The image collection and counts were performed separately by two individuals in a strictly blind manner so that the counter did not know from which barrel, or animal, the synapse belonged. Using the NIH Image software, a line was drawn along the presynaptic density, and the center of each identified vesicle was plotted. The length of the synapse and the nearest distance between the vesicle and the presynaptic membrane were measured. The vesicles were considered as "docked" if they were located up to one-vesicle diameter distance from the presynaptic density, and the reserve pool of vesicles were those outside this perimeter.

Statistical analysis. Quantitative results were tested for normality in each case, and when applicable, parametric statistics were used; in the cases in which data distribution was not normal, nonparametric analyses were applied.

\section{Results}

\section{Reduction in BDNF protein levels in the barrel cortex}

The levels of BDNF protein were measured in the barrel cortex of the BDNF heterozygote animals. This region of the somatosensory cortex was confirmed using Nissl-stained tangential sections. The protein level in the barrel cortex of the BDNF heterozygotes, as measured by BDNF ELISA, was $9.8 \pm 2.2$ ( $\mathrm{pg} / \mathrm{mg}$ total 


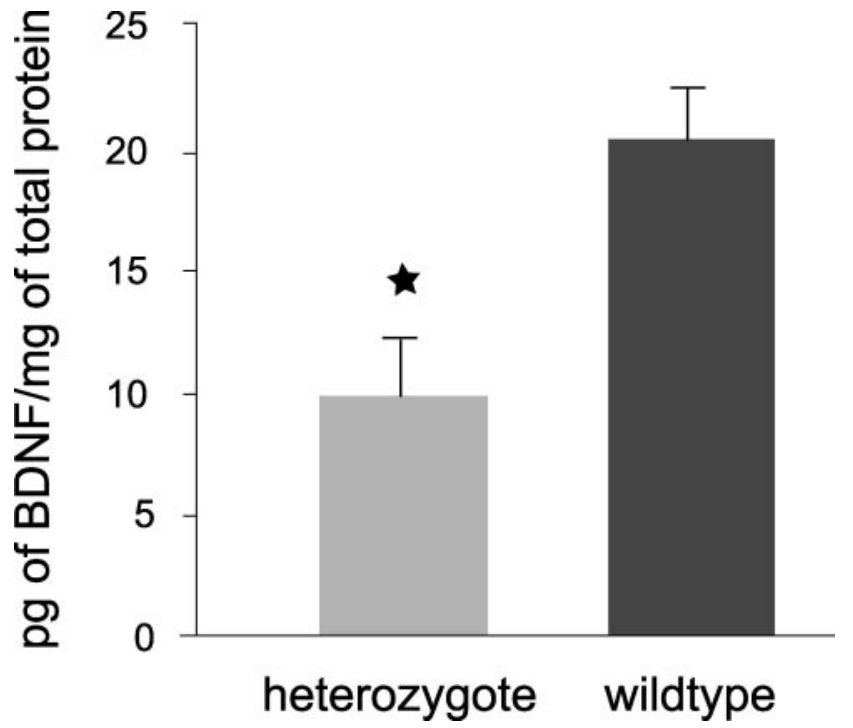

Figure 1. BDNF levels in the barrel cortex of BDNF knock-out heterozygous mice. BDNF protein levels in the barrel cortex in BDNF heterozygotes are reduced in comparison with control wild-type siblings. The protein level of six barrel cortices from three animal pairs was determined by ELISA. Data are expressed as the means \pm SD. ${ }^{*} p<0.01$ (Student's paired $t$ test).

protein), significantly lower (52\%) than that of wild-type siblings (20.4 $\pm 2.0 \mathrm{pg} / \mathrm{mg}$ total protein; $p<0.01$ ) (Fig. 1).

\section{Morphometric analysis of dendritic spines in wild-type and BDNF + / - mice}

We first analyzed the extent to which the BDNF $+/-$ mice are similar to the wild-type mice and whether or not a lower expression of BDNF leads to a spine morphology that is fundamentally different in adult animals. For the parameters listed in Table 1, spines from the two groups were identical, indicating that a reduced expression of BDNF does not alter spine morphology. We further calculated the volume occupied by dendrites and their spines as well as the total dendritic length. These measurements showed that, in terms of the amount of dendrite present, the neuropil sampled from wild-type and BDNF $+/-$ mice are identical (volume in wild-type, $18.14 \mu \mathrm{m}^{3} \pm 2.35$ in $100 \mu \mathrm{m}^{3}$ of neuropil; volume in BDNF $+/-, 20.56 \mu \mathrm{m}^{3} \pm 2.84$ in $100 \mu \mathrm{m}^{3}$ of neuropil; $p>0.5$ ANOVA; length of dendrite in $100 \mu \mathrm{m}^{3}$ from: wild-type, $79.02 \pm 6.77$; $\mathrm{BDNF}+/-, 80.62 \pm 14.96 ; p>$ 0.5 ANOVA).

After stimulation, the same comparisons were made (spine surface area and volume, non-GABAergic synapse surface area, and surface of contact with astrocytes) on 147 spines from stimulated barrels in the three wild-type mice and 148 spines in the stimulated barrels of the four BDNF $+/-$ mice. No significant differences were seen, except in spine volume (Table 1). The distribution of this parameter is shown in Figure 2. Whereas stimulation does not modify the distribution in the wild-type animals, in the stimulated barrels of BDNF $+/-$ mice the distribution was shifted significantly to larger values ( $p=0.03 ; \chi^{2}$ test).

Besides modifications in size, spines always had a single head; none was branched, indicating that the spine population in the barrel hollows of both sets of mice was similar. Of the spines that had two synapses, one was always excitatory, the other inhibitory. No spines were seen with more than two synapses.

It would seem, therefore, that a consequence of whisker stimulation in mice with a lower expression of BDNF is an increase in spine volume with no change in the synaptic surface area.

\section{Effect of whisker stimulation on the number of docked} vesicles in $\mathrm{BDNF}+/-$ and wild-type mice

The number of synaptic vesicles was counted in electron micrographs of non-GABAergic synapses on dendritic spines in the barrel hollows. Per synapse, two sets of vesicles were distinguished: those in the close vicinity of the presynaptic membrane, termed "docked," and the others, further away from the presynaptic membrane, non-docked vesicles within the reserve pool (see Materials and Methods) (Fig. 3). For both docked vesicles as well as those in the reserve pool, no difference was detected between the two groups of mice. The median number of docked vesicles per active zone in three wild-type mice was 2 [interquartile range (IQR; p25-p75), 1-3] and in three BDNF + / - mice was 3 (IQR, 2-3) (Mann-Whitney $U$ test; $p>0.5$ ). The median number of vesicles in the reserve pool of the wild-type mice was 7 (IQR, 4-8) and in the BDNF +/- mice was 7 (IQR, 6-8) (Man$n-W h i t n e y ~ U$ test; $p>0.5)$. After stimulation, there was no significant difference seen in either the number of docked vesicles of those in the reserve pool for either group of mice (Mann-Whitney $U$ test; $p>0.8)$. A reduced expression of BDNF, or whisker stimulation, does not seem to alter vesicle distribution in the excitatory synapses.

\section{Comparison of synaptic densities}

Between the wild-type and BDNF +/- mice, a comparison of the total synaptic density showed no significant difference in the unstimulated barrel hollows (wild-type, $0.92 \pm 0.06$ synapses $/ \mu \mathrm{m}^{3}$; BDNF $+/-, 0.97 \pm 0.2$ synapses $/ \mu \mathrm{m}^{3} ; p>0.5$; ANOVA). However, the three values obtained in the wild-type mice had a small variation between them (unstimulated barrel, 0.85-1.06), whereas the variation in the values obtained from the BDNF +/mice was significantly larger ( $p<0.05$; F-test of variance). These results suggest that a reduction in the level of BDNF does not seem to affect the mean density of synapses in the barrel hollows but, rather, influences the interindividual variation in synaptic density in the barrel hollow.

After $24 \mathrm{hr}$ of whisker stimulation, the synaptic density in the wild-type animals increased significantly by $17.6 \pm 8.0 \%(p<$ 0.05; ANOVA; from $0.92 \pm 0.06$ synapses $/ \mu \mathrm{m}^{3}$ to $1.07 \pm 0.03$ synapses $/ \mu \mathrm{m}^{3}$ ) (Fig. $4 A$ ). This difference is mainly attributable to an increase in GABAergic synapses (see below). In BDNF +/mice, the difference between the stimulated and unstimulated barrel was not significant ( $p>0.5$; ANOVA) with $0.94 \pm 0.14$ and $0.97 \pm 0.21$ synapses $/ \mu \mathrm{m}^{3}$ (Fig. $4 A$ ). Therefore, a reduced level of BDNF prevents the increase in synaptic density induced by continuous whisker stimulation.

\section{Density of GABAergic synapses}

The neuropil from the wild-type unstimulated barrel had a density of GABAergic synapses of $0.13 \pm 0.03$ synapses $/ \mu \mathrm{m}^{3}$, corresponding to $15.4 \pm 4.6 \%$ of the total synaptic density. These values were not significantly different from the values in the BDNF $+/-$ mice $\left(0.17 \pm 0.07\right.$ synapses $/ \mu \mathrm{m}^{3} ; p>0.5$; ANOVA), which is $17.3 \pm 4.9 \%$ of the total (Fig. $4 B$ ). This indicates that the reduced level of BDNF expression does not affect the overall balance between excitatory and inhibitory synapses in layer IV of the barrel cortex.

After whisker stimulation, in the wild-type mice, the density of GABAergic synapses increased significantly to $0.24 \pm 0.04$ synapses $/ \mu \mathrm{m}^{3}$, corresponding to a $75.1 \pm 22.1 \%$ increase in GABAergic synapses $(p<0.05$; ANOVA) (Fig. $4 B)$. This increase, however, was not observed in BDNF + / - mice (unstimulated, $0.17 \pm 0.07$; stimulated, $0.20 \pm 0.06 ; p>0.5$; ANOVA) 


\begin{tabular}{|c|c|c|c|c|}
\hline & Wild type $+/+$ & & $\mathrm{BDNF}+/-$ & \\
\hline & $\begin{array}{l}\text { Unstimulated } \\
\text { (98 spines) }\end{array}$ & $\begin{array}{l}\text { Stimulated } \\
\text { (147 spines) }\end{array}$ & $\begin{array}{l}\text { Unstimulated } \\
\text { (148 spines) }\end{array}$ & $\begin{array}{l}\text { Stimulated } \\
\text { (149 spines) }\end{array}$ \\
\hline Spine volume $\left(\mu \mathrm{m}^{3}\right)$ & $0.10(0.08)$ & $0.08(0.08)$ & $0.10(0.09)$ & $0.14(0.08)^{*}$ \\
\hline Spine surface area $\left(\mu \mathrm{m}^{2}\right)$ & $1.18(0.62)$ & $1.07(0.67)$ & $1.31(0.93)$ & $1.52(0.76)$ \\
\hline Non-GABA synapse surface area $\left(\mu \mathrm{m}^{2}\right)$ & $0.07(0.05)$ & $0.05(0.05)$ & $0.07(0.06)$ & $0.08(0.06)$ \\
\hline Spine surface area in contact with astrocyte $\left(\mu \mathrm{m}^{2}\right)$ & $0.27(0.39)$ & $0.29(0.37)$ & $0.19(0.30)$ & $0.38(0.07)$ \\
\hline Percentage of spine surface area involved in: & & & & \\
\hline Non-GABA synapse & $5.86(3.20)$ & $5.60(3.89)$ & $5.80(3.20)$ & $5.41(3.22)$ \\
\hline Contact with astrocyte & $21.75(8.68)$ & $27.02(8.06)$ & $22.96(7.41)$ & $25.27(7.24)$ \\
\hline Surface area of GABA synapse on spines $\left(\mu \mathrm{m}^{2}\right.$; & & & & \\
\hline number sampled in parentheses) & $0.04(0.03)(5)$ & $0.03(0.01)(8)$ & $0.04(0.02)(4)$ & $0.03(0.02)(7)$ \\
\hline
\end{tabular}

Summary of the morphometric data obtained from the reconstructed spines of the unstimulated (B2) and stimulated (C2) barrel in the two groups of mice: $+/+(n=3)$ and $+/-(n=4)$. The number of spines is indicated in parentheses in the top row, and that of GABAergic synapses in the bottom row. All data are presented as median (range). The volume of spines in the stimulated barrel hollows of $+/-$ mice is significantly larger compared with unstimulated one (Mann-Whitney $U$ test; ${ }^{*} p<0.05$ ). All other parameters did not alter significantly on stimulation.

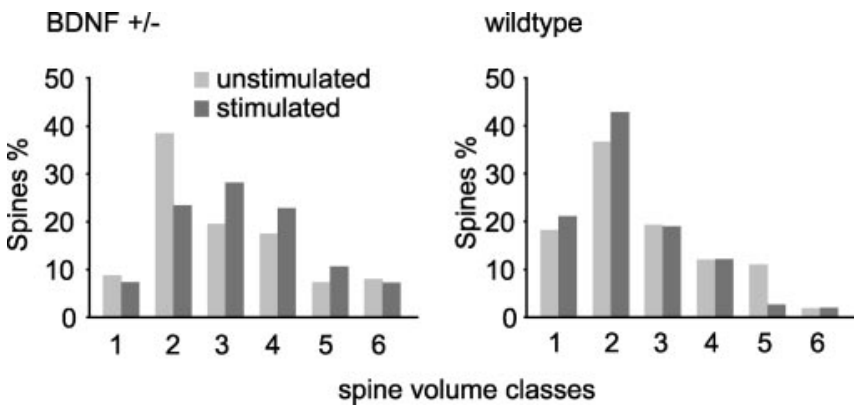

Figure 2. Frequency distribution of spine volume differs in stimulated barrel of BDNF $+1-$ mice. Spines are distributed in classes based on their volume (in micrometers cubed), and the relative distribution is shown for BDNF $+/-(n=4$; left) and wild-type mice ( $n=3$; right) separately. In the BDNF $+1-$ mice, whisker stimulation shifts the distribution toward spines with significantly larger volume ( $\chi^{2}$ test on five classes; $p=0.03$ ), whereas there is no significant difference between the distribution of spine volumes in the unstimulated and stimulated barrel in wild-type mice ( $\chi^{2}$ test on five classes; $p>0.5$ ).

(Fig. $4 B$ ). So, the reduced expression of BDNF may impair the potential of GABAergic innervation to act on prolonged whisker stimulation.

\section{Spine density}

As mentioned above, the spine volume in unstimulated barrels between wild-type and BDNF $+/-$ mice is the same. Between these two groups, before and after whisker stimulation, there was also no significant change in the density of dendritic spines (unstimulated $+/+, 0.55 \pm 0.13$ spines $/ \mu \mathrm{m}^{3}$; stimulated $+/+$, $0.73 \pm 0.01$; unstimulated $+/-, 0.66 \pm 0.17$; stimulated $+/-$, $0.62 \pm 0.12 ; p>0.1$, ANOVA). Additional classification of the spines receiving more than one synapse, however, showed that there was a significant increase in the number of GABAergic synapses onto spines (Fig. 4C). In the unstimulated barrel in $+/+$ mice, the density of spines with two synapses is $0.03 \pm 0.01 / \mu \mathrm{m}^{3}$ (Fig. 4C). In the stimulated barrel, it increases to reach $0.08 \pm$ $0.01 / \mu \mathrm{m}^{3}$. Clearly, in the wild-type mice, a $24 \mathrm{hr}$ period of whisker stimulation caused a marked increase of double innervated spines (171.4 \pm 97.6\%; $p<0.05$; ANOVA) (Fig. $4 C$ ). In the $\mathrm{BDNF}+/-$ mice, however, there was no increase in the density of inhibitory synapses on spines (unstimulated barrel, $0.05 \pm$ 0.03 ; stimulated barrel, $0.06 \pm 0.03 ; p>0.1$ ) (Fig. $4 C$ ). It is of note that, in the unstimulated barrel, the $+/-$ mice have the same density of these specific synapses as the $+/+$ controls $(p>$ 0.1 ; ANOVA).

Morphometric measurements of the spines that had two syn-
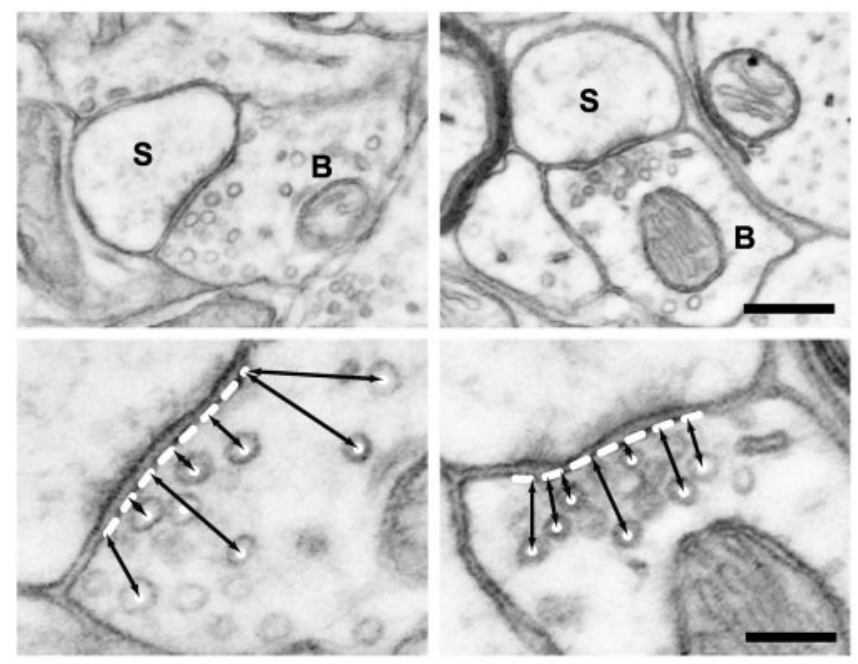

Figure 3. Examples of two synapses used to count docked and reserve pool vesicles. The electron micrographs show the synapses in the top panels and their corresponding higher magnifications below, indicating the distances that were measured (double-headed black arrows) from the center of the vesicles (white spot) to the presynaptic membrane (dashed white line). Docked vesicles were defined as vesicles within $75 \mathrm{~nm}$ from the presynaptic membrane; reserve pool vesicles are all the vesicles further than $75 \mathrm{~nm}$ from the presynaptic density (see Materials and Methods). Scale bars: top, $0.2 \mu \mathrm{m}$; bottom, $0.1 \mu \mathrm{m}$. S, Dendritic spine; B, axonal bouton.

apses showed that the surface covered by the excitatory synapse was not influenced by insertion of a second inhibitory synapse. The surface of inhibitory synapse was, indeed, stable between the four groups (mean inhibitory synaptic surface area, $0.03 \pm 0.01$ $\mu \mathrm{m}^{2}$ ). Moreover, the GABAergic synapses on spines were always macular and seen on either the head or neck of the spines. In contrast, the non-GABAergic synapses had complex shapes and were always on the spine head (Fig. 5).

\section{Discussion}

BDNF+/ - mice were used to study whisker stimulationinduced synaptogenesis in the barrel cortex. The main findings can be summarized as: (1) the neuropil in the barrel hollows of adult BDNF +/ - and wild-type mice appear to be identical; (2) although whisker stimulation induced a significant increase in the density of synapses on spines in $+/+$ animals, this increase was not observed in BDNF+/- mice; (3) a dramatic increase in the density of double-synapse spines (one excitatory and one inhibitory) was seen in $+/+$, but not in $\mathrm{BDNF}+/-$, animals; and (4) whisker stimulation elicited an increase in spine size in 
$\mathrm{BDNF}+/-$, but not in wild-type mice. These findings support the view that activity-induced changes in synapse number and morphology are mediated by BDNF and provide important insights into the mechanisms underlying the structural plasticity of CNS synapses in the adult cerebral cortex.

Activity-dependent expression of BDNF mRNA has been observed in various brain regions associated with synaptic plasticity. In the whisker-to-barrel pathway, unilateral stimulation of a set of whiskers results in a significant increase in BDNF mRNA in the barrel corresponding to the stimulated whisker (Rocamora et al., 1996), with the most dramatic increase observed in layer IV. BDNF gene expression is markedly enhanced in hippocampal slices in response to LTP-inducing stimuli (Patterson et al., 1992; Dragunow et al., 1993). The level of BDNF mRNA is also rapidly and selectively increased in the hippocampus during learning and memory (Hall et al., 2000; Mizuno et al., 2000). In the visual cortex, the expression of BDNF is regulated by visual inputs (Castren et al., 1992; Schoups et al., 1995; Pollock et al., 2001), and monocular deprivation elicits a striking decrease in BDNF mRNA and protein in the corresponding part of the visual cortex (Bozzi et al., 1995; Rossi et al., 1999; Lein and Shatz, 2000).

\section{The neuropil of BDNF $+/-$ mice}

It was previously shown that the $\mathrm{BDNF}+/-$ mice are comparable with the wild-type animals in terms of peripheral sensory systems (Ernfors et al., 1994). Also, the development of the cerebral cortex and its topographic maps, including barrel formation, is not modified by a reduced level of BDNF (Itami et al., 2000). In the visual cortex, the ocular dominance plasticity is normal in $\mathrm{BDNF}+/-$ mice (Bartoletti et al., 2002). The reduced level of BDNF, however, affects the induction of LTP at the CA1 synapses in the hippocampus (Korte et al., 1995) as well as at layer IV to layer III synapses in the visual cortex (Bartoletti et al., 2002). This implies a threshold effect whereby a lower level of BDNF expression during development does not affect the establishment of a normal complement of synapses. During circuit formation, if the level of BDNF in heterozygote mice is near threshold, other uncontrolled factors may significantly influence synaptogenesis, leading to large variations among littermates, as seen in this study. However, during adulthood and situations of plasticity, the BDNF level may be insufficient, resulting in an abnormal response with neurons incapable of modifying their connectivity.

Our data also show that although a reduction in the BDNF level did not result in major modifications in the density of excitatory or inhibitory synapses in unstimulated barrels, there were larger variabilities in total synaptic density, density of GABAergic synapses, as well as the density of double innervated spines in the $\mathrm{BDNF}+/-$ mice. These variabilities are unlikely to be attributable to genetic differences, hormonal fluctuations, or age differences because the animals used in this study were littermates. More likely is the possible role of BDNF during development in controlling synaptic density.

Despite no induction of synapse formation in these heterozygote animals, we did observe an increase in spine volume, suggesting little impairment of the signal transmission to the somatosensory cortex. Spine volume changes have previously been
B

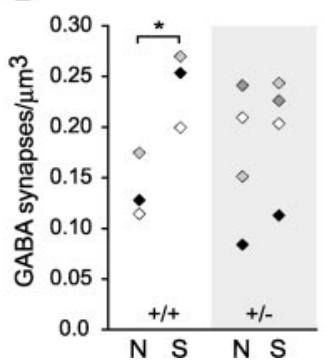

C

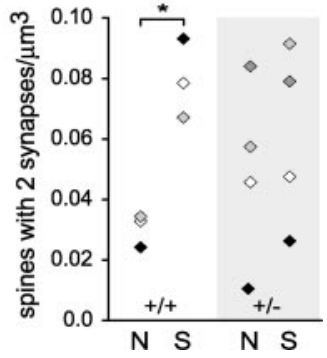

Figure 4. Effect of sensory stimulation in the barrels of wild-type and BDNF $+/-$ mice. The densities of all synapses $(A)$, GABAergic synapses $(B)$, and spines with two synapses ( $C$ ) are shown for unstimulated and stimulated barrels. A stimulated (C2) ( represents the density (number of synapses per cubic micrometer) within the sampled neuropil from each mouse Each color

observed in response to alterations in various mediators of calcium buffering and transport (Korkotian and Segal, 1999; Vecellio et al., 2000; Sabatini et al., 2002). These studies describe changes in calcium concentration affecting the spine volume. We suggest, therefore, that if spines are unable to gain an inhibitory synapse, increased excitation will lead to a greater influx of $\mathrm{Ca}$ ions leading to increased spine volume.

Previous studies using the same mice showed that the number of docked vesicles was decreased at the hippocampal CA1 synapses (Pozzo-Miller et al., 1999), as well as at the synapses between parallel fibers and the Purkinje cells in the cerebellum (Carter et al., 2002). In contrast, synapses in layer IV of the barrel cortex of these mice did not show a significant difference in total synaptic vesicles at excitatory synapses or those that were considered to be docked. These results indicate that, on the one hand, the role of BDNF in synaptic vesicle distribution could be restricted to certain populations of synapses and, on the other hand, suggest that layer IV synapses in the barrel cortex of BDNF $+/-$ mice are structurally normal and, therefore, capable of handling the altered sensory input during whisker stimulation.

\section{Implications and mechanistic considerations}

The whisker-to-barrel pathway is uniquely suited for studying morphological modifications of synapses in the adult brain in vivo. Stimulation of whiskers induces a series of changes in the barrel cortex, leading to a selective increase in the number of synapses corresponding to the activated barrel. In particular, there is a persistent increase in the number of double-innervated synapses with a GABAergic bouton on the spine (Knott et al., 2002). We demonstrated that a reduction in BDNF expression prevents all of these morphological changes induced by peripheral stimulation. These results are significant for several reasons. The study reveals a potential molecular mechanism for the activity-dependent modulation of the number and morphology of synapses in the adult brain. Other studies showed a role for BDNF in morphological alterations of neurons. In vitro, BDNF stimulates the growth of dendritic spines in cultured hippocampal neurons (Murphy et al., 1998; Tyler and Pozzo-Miller, 2001). Furthermore, BDNF was shown to affect only the dendritic development of inhibitory interneurons and not excitatory interneurons (Kohara et al., 2003). This selectivity of BDNF reinforces the idea that growth factors like BDNF are important for the development of inhibitory neurons (Marty et al., 1997) that could, therefore, affect such important events as the promotion 


\section{A}

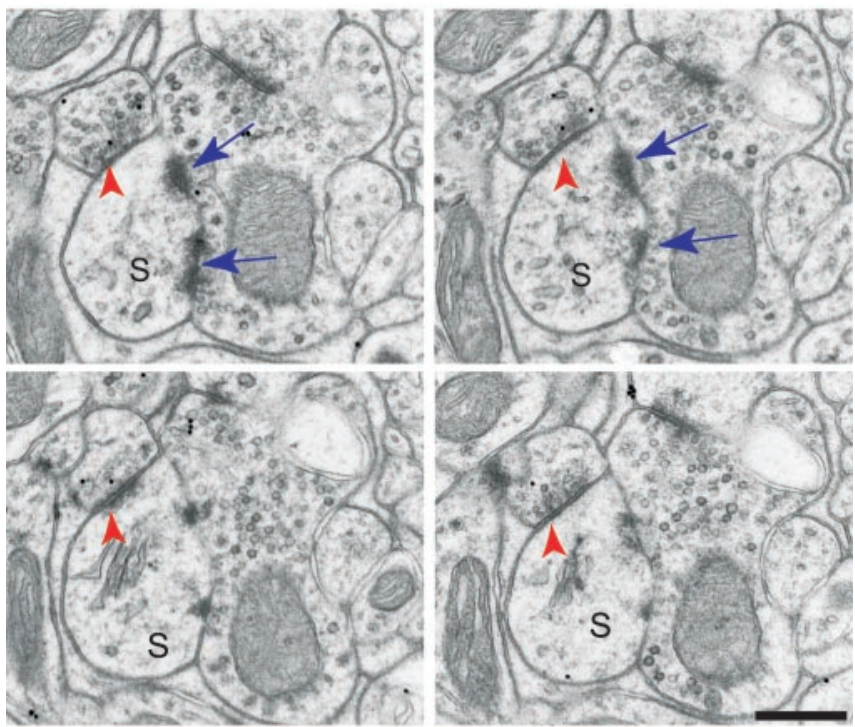

B

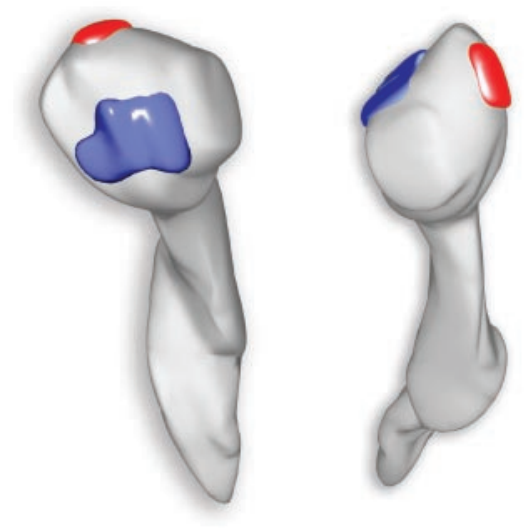

Figure 5. A subgroup of spines has two synapses, one GABA positive and one GABA negative. A series of four images $(A)$ shows a spine with two synapses found in the neuropil of a stimulated barrel in a wild-type animal. Serial sections were processed for GABA immunohistochemistry, and gold particles (appearing as solid black spots of small diameter) are found in structures containing GABA. The GABA-positive presynaptic bouton forms a symmetric synapse (arrowhead) with the spine $(S)$, which receives a second asymmetric synapse (arrow) that appears in two parts with a GABA-negative axonal bouton. $B$, Three-dimensional reconstruction of this spine. The GABA-negative synapse is blue, and the GABA-positive synapse is red. Scale bar, $0.25 \mu \mathrm{m}$.

of cortical inhibition, leading to changes in the regulation of critical periods, as has been demonstrated in the visual system (Huang et al., 1999). From our data, it is conceivable, therefore, that the increase in BDNF mRNA and subsequent BDNF protein would promote the formation of new synapses in the barrel corresponding to the change in peripheral sensory stimulation. Although regulation of BDNF mRNA transcription by neuronal activity seems to be a general phenomenon, its physiological significance has not been established. In the hippocampus, LTPinducing stimuli reliably increase the level of BDNF mRNA in CA1 and dentate gyrus (Patterson et al., 1992; Dragunow et al., 1993), but this phenomenon has not been linked directly to the induction or maintenance of hippocampal LTP. In the visual cortex, monocular deprivation in cat leads to a reduction in the BDNF mRNA level specifically in the ocular dominance columns corresponding to the deprived eye (Lein and Shatz, 2000). Whis- ker stimulation has been shown to induce the expression of BDNF mRNA in a barrel-specific manner (Rocamora et al., 1996). The peak of BDNF mRNA expression precedes the alterations in synaptic density and morphology induced by whisker stimulation (Knott et al., 2002). We now report that a wellcharacterized form of experience-dependant synaptic change is prevented in the barrel cortex of $\mathrm{BDNF}+/-$ mice. Our results suggest that the structural plasticity observed in the barrel cortex is mediated by BDNF.

\section{References}

Bartoletti A, Cancedda L, Reid SW, Tessarollo L, Porciatti V, Pizzorusso T, Maffei L (2002) Heterozygous knock-out mice for brain-derived neurotrophic factor show a pathway-specific impairment of long-term potentiation but normal critical period for monocular deprivation. J Neurosci 22:10072-10077.

Bozzi Y, Pizzorusso T, Cremisi F, Rossi FM, Barsacchi G, Maffei L (1995) Monocular deprivation decreases the expression of messenger RNA for brain-derived neurotrophic factor in the rat visual cortex. Neuroscience 69:1133-1144.

Bronchti G, Corthesy ME, Welker E (1999) Partial denervation of the whiskerpad in adult mice: altered patterns of metabolic activity in barrel cortex. Eur J Neurosci 11:2847-2855.

Cabelli RJ, Hohn A, Shatz CJ (1995) Inhibition of ocular dominance column formation by infusion of NT-4/5 or BDNF. Science 267:1662-1666.

Carter AR, Chen C, Schwartz PM, Segal RA (2002) Brain-derived neurotrophic factor modulates cerebellar plasticity and synaptic ultrastructure. J Neurosci 22:1316-1327.

Castren E, Zafra F, Thoenen H, Lindholm D (1992) Light regulates expression of brain-derived neurotrophic factor mRNA in rat visual cortex. Proc Natl Acad Sci USA 89:9444-9448.

Coggeshall RE, Lekan HA (1996) Methods for determining numbers of cells and synapses: a case for more uniform standards of review. J Comp Neurol 364:6-15.

Dragunow M, Beilharz E, Mason B, Lawlor P, Abraham W, Gluckman P (1993) Brain-derived neurotrophic factor expression after long-term potentiation. Neurosci Lett 160:232-236.

Ernfors P, Lee KF, Jaenisch R (1994) Mice lacking brain-derived neurotrophic factor develop with sensory deficits. Nature 368:147-150.

Fiala JC, Harris KM (2001) Extending unbiased stereology of brain ultrastructure to three-dimensional volumes. J Am Med Inform Assoc 8:1-16.

Figurov A, Pozzo-Miller LD, Olafsson P, Wang T, Lu B (1996) Regulation of synaptic responses to high-frequency stimulation and LTP by neurotrophins in the hippocampus. Nature 381:706-709.

Fox K, Glazewski S, Chen CM, Silva A, Li X (1996) Mechanisms underlying experience-dependent potentiation and depression of vibrissae responses in barrel cortex. J Physiol Paris 90:263-269.

Gierdalski M, Jablonska B, Smith A, Skangiel-Kramska J, Kossut M (1999) Deafferentation induced changes in GAD67 and GluR2 mRNA expression in mouse somatosensory cortex. Brain Res Mol Brain Res 71:111-119.

Hall J, Thomas KL, Everitt BJ (2000) Rapid and selective induction of BDNF expression in the hippocampus during contextual learning. Nat Neurosci 3:533-535.

Huang ZJ, Kirkwood A, Pizzorusso T, Porciatti V, Morales B, Bear MF, Maffei L, Tonegawa S (1999) BDNF regulates the maturation of inhibition and the critical period of plasticity in mouse visual cortex. Cell 98:739-755.

Itami C, Mizuno K, Kohno T, Nakamura S (2000) Brain-derived neurotrophic factor requirement for activity-dependent maturation of glutamatergic synapse in developing mouse somatosensory cortex. Brain Res 857:141-150.

Jones EG, Woods TM, Manger PR (2002) Adaptive responses of monkey somatosensory cortex to peripheral and central deafferentation. Neuroscience 111:775-797.

Knott GW, Quairiaux C, Genoud C, Welker E (2002) Formation of dendritic spines with GABAergic synapses induced by whisker stimulation in adult mice. Neuron 34:265-273.

Kohara K, Kitamura A, Adachi N, Nishida M, Itami C, Nakamura S, Tsumoto T (2003) Inhibitory but not excitatory cortical neurons require presynaptic brain-derived neurotrophic factor for dendritic development, as revealed by chimera cell culture. J Neurosci 23:6123-6131.

Korkotian E, Segal M (1999) Release of calcium from stores alters the mor- 
phology of dendritic spines in cultured hippocampal neurons. Proc Natl Acad Sci USA 96:12068-12072.

Korte M, Carroll P, Wolf E, Brem G, Thoenen H, Bonhoeffer T (1995) Hippocampal long-term potentiation is impaired in mice lacking brain- derived neurotrophic factor. Proc Natl Acad Sci USA 92:8856-8860.

Lein ES, Shatz CJ (2000) Rapid regulation of brain-derived neurotrophic factor mRNA within eye-specific circuits during ocular dominance column formation. J Neurosci 20:1470-1483.

Marty S, Berzaghi Mda P, Berninger B (1997) Neurotrophins and activitydependent plasticity of cortical interneurons. Trends Neurosci 20:198-202.

Melzer P, Van der Loos H, Dorfl J, Welker E, Robert P, Emery D, Berrini JC (1985) A magnetic device to stimulate selected whiskers of freely moving or restrained small rodents: its application in a deoxyglucose study. Brain Res 348:229-240.

Mizuno M, Yamada K, Olariu A, Nawa H, Nabeshima T (2000) Involvement of brain-derived neurotrophic factor in spatial memory formation and maintenance in a radial arm maze test in rats. J Neurosci 20:7116-7121.

Murphy DD, Cole NB, Segal M (1998) Brain-derived neurotrophic factor mediates estradiol-induced dendritic spine formation in hippocampal neurons. Proc Natl Acad Sci USA 95:11412-11417.

Patterson SL, Grover LM, Schwartzkroin PA, Bothwell M (1992) Neurotrophin expression in rat hippocampal slices: a stimulus paradigm inducing LTP in CAl evokes increases in BDNF and NT-3 mRNAs. Neuron 9:1081-1088.

Patterson SL, Abel T, Deuel TA, Martin KC, Rose JC, Kandel ER (1996) Recombinant BDNF rescues deficits in basal synaptic transmission and hippocampal LTP in BDNF knockout mice. Neuron 16:1137-1145.

Pollock GS, Vernon E, Forbes ME, Yan Q, Ma YT, Hsieh T, Robichon R, Frost DO, Johnson JE (2001) Effects of early visual experience and diurnal rhythms on BDNF mRNA and protein levels in the visual system, hippocampus, and cerebellum. J Neurosci 21:3923-3931.

Pozzo-Miller LD, Gottschalk W, Zhang L, McDermott K, Du J, Gopalakrishnan R, Oho C, Sheng ZH, Lu B (1999) Impairments in high-frequency transmission, synaptic vesicle docking, and synaptic protein distribution in the hippocampus of BDNF knockout mice. J Neurosci 19:4972-4983.

Rocamora N, Welker E, Pascual M, Soriano E (1996) Upregulation of BDNF mRNA expression in the barrel cortex of adult mice after sensory stimulation. J Neurosci 16:4411-4419.

Rossi FM, Bozzi Y, Pizzorusso T, Maffei L (1999) Monocular deprivation decreases brain-derived neurotrophic factor immunoreactivity in the rat visual cortex. Neuroscience 90:363-368.

Sabatini BL, Oertner TG, Svoboda K (2002) The life cycle of $\mathrm{Ca}(2+)$ ions in dendritic spines. Neuron 33:439-452.

Schoups AA, Elliott RC, Friedman WJ, Black IB (1995) NGF and BDNF are differentially modulated by visual experience in the developing geniculocortical pathway. Brain Res Dev Brain Res 86:326-334.

Trachtenberg JT, Chen BE, Knott GW, Feng G, Sanes JR, Welker E, Svoboda $\mathrm{K}$ (2002) Long-term in vivo imaging of experience-dependent synaptic plasticity in adult cortex. Nature 420:788-794.

Tyler WJ, Pozzo-Miller LD (2001) BDNF enhances quantal neurotransmitter release and increases the number of docked vesicles at the active zones of hippocampal excitatory synapses. J Neurosci 21:4249-4258.

Vecellio M, Schwaller B, Meyer M, Hunziker W, Celio MR (2000) Alterations in Purkinje cell spines of calbindin D-28 k and parvalbumin knockout mice. Eur J Neurosci 12:945-954.

Welker E, Rao SB, Dorfl J, Melzer P, van der Loos H (1992) Plasticity in the barrel cortex of the adult mouse: effects of chronic stimulation upon deoxyglucose uptake in the behaving animal. J Neurosci 12:153-170. 